\title{
Impact of ICT Based Extension Services on Dairy Production and Household Welfare: The Case of iCow Service in Kenya
}

\author{
Mwita Erick Marwa ${ }^{1}$, John Mburu ${ }^{1}$, Rao Elizaphan James Oburu ${ }^{2}$, Okeyo Mwai ${ }^{2}$ \& Susan Kahumbu ${ }^{2}$ \\ ${ }^{1}$ Department of Agricultural Economics, University of Nairobi, Nairobi, Kenya \\ ${ }^{2}$ International Livestock Research Institute, Nairobi, Kenya \\ ${ }^{3}$ Green Dream TECH Ltd, Nairobi, Kenya \\ Correspondence: Mwita Erick Marwa, Department of Agricultural Economics, College of Agriculture and \\ Veterinary Sciences, University of Nairobi, P.O. Box 29053-00625, Nairobi, Kenya. Tel: 254-723-536-703. \\ E-mail: mwitaerick@gmail.com
}

Received: October 13, 2019

Accepted: December 20, 2019 Online Published: February 15, 2020

doi:10.5539/jas.v12n3p141

URL: https://doi.org/10.5539/jas.v12n3p141

The research is financed by International Livestock Research Institute (ILRI) under the African Dairy Genetic Gain (ADGG) Project.

\begin{abstract}
Smallholder dairy farmers have the challenges of accessing timely and reliable agricultural information, and this limits them from realizing maximum farm output. The use of information and communication technologies (ICT) as a farming extension tool by smallholder farmers has the potential to reverse the scenario and improve farmers' outputs and incomes leading to increased welfare. This study employed the Propensity score Matching approach to evaluate the impacts of ICT-based extension services, in this case, iCow services on milk production, milk income, and household income using cross-sectional data from a survey of dairy farmers in Uasin Gishu, Nyandarua and Bomet counties of Kenya. The use of ICT-based iCow services is shown to increase Annual milk production per cow, milk income, and household income by $13 \%, 29 \%$, and $22 \%$, respectively. Partnerships between network providers and research institutes should be encouraged as part of bridging the extension gap occasioned by reduced public expenditure on extension services.
\end{abstract}

Keywords: iCow services, ICT, agricultural information, dairy farmers, propensity score matching, extension, husbandry practices

\section{Introduction}

Rural services are at the heart of thriving agricultural and rural development (ARD) in developing countries. Effective delivery of services is seen as 'essential if small farms in high potential areas are to intensify production, contribute to economic growth, and reduce poverty' (Milu \& Jayne, 2006). Agricultural extension is one of the services that play an essential role in the growth and transformation of the agrarian sector in Sub Saharan Africa (SSA), Kenya included (Joseph \& Polytechn, 2017; Mukembo \& Edwards, 2016). Indeed, benefits like high productivity, quality of produce, reduction of diseases and pests, and subsequent increase in income among smallholder farmers can be attributed to access to quality extension service (Fu \& Akter, 2012). Specifically, in livestock, such benefits are gained through use of information like patterns in livestock prices, good livestock management practices, and marketing (Milu \& Jayne, 2006).

In Kenya, agricultural extension services are delivered by multiple providers, which include; National government, county governments, agro-inputs manufacturers and suppliers and Non-government Organizations (NGOs). Extension services in Kenya have evolved over time, beginning with the Transfer of Technologies (ToT) approach, which emphasized the adoption of technologies with little regard, if any, for how knowledge and skills about using these technologies were acquired. The system failed to inspire a wider uptake of techniques, and this led to introduction of the Farming Systems Research (FSR) in the 1970s. FSR focused on on-farm testing and refining of technologies but also could not adequately address the multiple and often diverse needs of farmers (Mukembo \& Edwards, 2016). 
Later in the 1980s, Training and Visit (T\&V) approach was introduced with the aim of transferring information and technology through extension workers and contact farmers to the general farming community. However, $\mathrm{T} \& \mathrm{~V}$ could not address the varying needs of farmers due to high expenses and low coverage of extension workers. To improve the situation, a new extension approach based on Farmer Field School (FFS) was introduced in 2001. The FFS uses participatory methods in enhancing farmers' knowledge and skills on the use of agricultural technologies. While the technique somehow improved the productivity of farmers, the approach did not fully meet their diverse needs (Mukembo \& Edwards, 2016).

Given the limitations of previous approaches, extension services continue to evolve with players exploring new approaches, including the application of information and communication technologies (ICTs) in delivering advisory services. Studies show that the use of ICT in the farming community increases their production and income leading to increased welfare (Nyaga, 2012; Singh, 2006; Das, 2014). According to Duncombe (2012), the adoption of ICTs in the agricultural sector has yielded substantial economic, environmental and social benefits at local, nationwide and global stages. The use of ICTs by extension agents in gathering, retrieving, adapting, and disseminating a broad range of information needed by rural farming communities have made positive contributions towards rural development (Ajani \& Agwu, 2012). A report by Fu and Akter (2012) concluded that use of mobile phone technology among farming communities improves the quality and speed of the delivery of extension services. In line with these developments, several ICT-based programs have mushroomed in Kenya to address the challenge of low farm productivity and improve agricultural performance among smallholder farm households. These programs include; iCow, Kenya Agricultural Commodity Exchange (KACE), National Livestock Market Information System (NLMIS), Regional Agricultural Trade Intelligence Network (RATIN), National Farmers Information Service (NAFIS) and M- farm among others.

This study focuses on the iCow's ICT-platform and services, as a tool for dissemination of information among smallholder dairy farmers. The iCow services are offered by Green Dream Technology (GDT) in partnership with the Safaricom Foundation and International Livestock Research Institute (ILRI) with the aim of improving extension services among smallholder farmers. The iCow platform achieves this through a cost-effective, scalable mobile phone extension service, which provides farmers with basic, pure, timely knowledge and digital solutions that would improve their production. The iCow platform offers innovative products that include weekly messages on various livestock and agricultural topics, livestock calendars, farmer SMS library, and an expert directory. It is conceptualized that the digital information on vaccination, spraying, mastitis control, deworming, hygiene, and other dairy management practices improves animal health, reduces incidences of disease outbreak, and consequently reducing the intake of antibiotics. Nutrition also improves due to information on fodder management, proper feeding, and feed quality. Additionally, information on record-keeping helps farmers to enhance planning and forecasting. The expectation is that farmers participating in iCow would use the acquired technical knowledge and apply superior production technologies and husbandry practices to realize higher outputs and consequently improving their incomes.

Although previous studies have assessed the use of ICTs in agriculture, most of these studies focused on the application of ICT tools in market information systems (MIS) (Okello et al., 2013; Oyeyinka \& Bello, 2013; Hassan et al., 2008). Additionally, more attention has been given on the use of ICTs by extension officers (Fu \& Akter, 2012; Tata \& Mcnamara, 2018), there remains dearth research on the use of ICT extension tools by smallholder farmers. This study was designed to evaluate the impacts of the iCow services on milk production and household income among smallholder dairy farmers in Kenya. The paper is organized as follows. Section 2 describes the methodology used in the study. Section 3 presents and discusses estimation results, while section 4 makes concluding remarks and draws policy implications.

\section{Method}

\subsection{Theoretical Framework}

The study uses the theory of expected utility as developed by Bernoulli (1738), which has been applied in several studies on farmer decision-making in many aspects (Stearns, 2000; Babcock \& Hennessy, 1996; Gómez et al., 2004). Following Bernoulli (1738), participation in iCow ICT program can be viewed as a binary choice decision problem by farm households that try to maximize utility or net returns. The utility is determined by a set of variables $Z$, which influences the cost of adjusting to a new extension approach involving ICT (such as the cost of acquiring a mobile phone and the time spent on reviewing messages relayed by the platform). Variables in $Z$ also determine the relative returns that a farmer can earn from adopting iCow approach to extension. Thus, $Z$ can include household characteristics such as educational status and farming experience, 
both of which influence ability to synthesize relayed information and optimize farm decisions based on the provided information.

The probability that farmers participate in iCow platform is therefore determined by a comparison of the expected utility of participation in iCow extension program, $U_{i p}$, against the expected utility of participating in conventional extension program, $U_{i N}$. In making this comparison, farmers evaluate the benefits of adjustment mentioned above. Farmers, therefore, join in iCow program only if $U_{i p}>U_{i N}$, implying that the potential benefits outweigh the constraints, and this difference in utility can be represented by a latent variable, $R^{*} \cdot R_{i}^{*}=$ $U_{i p}-U_{i N}>0$. However, $R_{i}^{*}$ is a latent variable; what is observed is actual participation in iCow program, $R_{i}$, with $R_{i}=1$ if $U_{i p}>U_{i N}$ and $R_{i}=0$ if $U_{i p} \leq U_{i N}$. Participation in iCow program can, therefore, be represented as follows:

$$
R=Z \alpha-v
$$

Where, $\alpha$ is a vector of parameters, and $v$ is an error term with zero mean and variance $\sigma^{2}$. Since farmers are heterogeneous in their characteristics, not all of them will participate in the iCow program. For those who do, participation is expected to result in higher farm returns that may also affect household livelihood outcomes such as income.

\subsection{Impact Evaluation}

Program evaluation often follows approaches suggested by (Maddala, 1991)

$$
y=\beta X_{1}+\gamma R+\varepsilon
$$

Where, $y$ can be considered as one of the livelihood outcomes such as household income and milk yield.

In this study, milk production was computed accounting for the breed type and lactation length of the lactating cows, while milk production per cow was calculated by dividing total milk production in a household by the number of lactating cows. Household income was calculated by summing up, revenue from milk, farm income, and off-farm income. $X_{1}$ is a vector of the farm, household and contextual characteristics that could influence livelihood outcomes, and; $R$ is a dummy indicating whether a household uses iCow services. We hypothesize that use of iCow services could influence livestock husbandry practices and uptake of improved technologies, leading to higher yields, adjusted dairy income and subsequently household income. Holding other factors constant, therefore, the coefficient $(\gamma)$ captures partial effects of household uptake of iCow services. However, households may self-select into uptake of iCow services leading to bias estimates of treatment effects of iCow extension services. For instance, it is possible that some factors determining uptake of iCow services may also affect household income. If such factors are not included explicitly in Equation (2), as is the case when such variables are unobserved, then the indicator for uptake of iCow services in Equation (2) will be correlated with the error term $\left(\varepsilon_{1}\right)$, leading to a biased estimation of $\gamma$.

One way to address this problem is to monitor users and non-users of iCow services over time and then apply difference-in-difference (DiD) analytical techniques to isolate the impact of iCow services on livelihood outcomes. However, such an approach cannot be applied to this study since monitoring of the use of iCow services was restricted to the treated households. An alternative approach that also addresses selection bias is the instrumental variables (IV) (Ichimura, 1997). However, the application of the IV approach is limited by the difficulty in finding a suitable IV that influences the probability of treatment without having a correlation to the error term (Wooldrige, 2011). One could also apply regression discontinuity (RD) method that fits regression line to estimate the average effects based on the outcomes of interest (Khandker et al., 2010). However, it is not always easy to establish selection criteria.

To address the potential selection bias, we, therefore, apply propensity score matching (PSM) approach that assumes that conditioning on observable variables eliminates sample selection bias (Heckman \& Navarro-Lozano, 2004). Matching essentially creates an experimental condition in which uptake of iCow services is randomly assigned, allowing for identification of a causal link between the use of iCow services and livelihood outcomes. Instead of directly comparing outcome and impact variables between users and non-users of iCow services, PSM restricts comparison to households that are similar in terms of observable characteristics and therefore reduces the bias that would otherwise occur if the two groups were systematically different (Dehejia, 2002).

\subsection{The Propensity Score Matching Method (PSM) Method}

PSM involves constructing a comparison group based on an individual's probability of participating in a program conditional on observable characteristics (Ravallion, 2009; Khandker et al., 2010). This proceeds in 
two-stage: first, we use the entire sample to estimate a probit/logit model that generates propensity scores $\boldsymbol{P}(\boldsymbol{z})$ estimates of the probability that a household with a vector of characteristics $z$, will use iCow services. The vector $\boldsymbol{z}$ are assumed to be those observable variables that determine whether a household uses iCow services. In this estimation, households with similar observable characteristics are likely to have identical propensity scores $\boldsymbol{P}(\boldsymbol{z})$, even if some of them do not use iCow services.

Using similarity in propensity scores, we can, therefore, construct comparable groups of households with similar propensity scores $\boldsymbol{P}(\boldsymbol{z})$ but where one group uses iCow services while the other group of households does not use iCow services. In the second stage, we calculate the average outcomes for the two groups and then estimate the impacts of iCow services as the difference in average outcomes between these groups. This difference is known as the PSM estimator of average treatment effect on the treated households (ATT), which is expressed as follows:

$$
\tau_{\mathrm{ATT}}^{\mathrm{PSM}}=\mathrm{E}_{\mathrm{P}(\mathrm{z} \mid \mathrm{R}=1)}\left[\mathrm{E}\left\{\mathrm{Y}_{1} \mid \mathrm{R}=1, \mathrm{P}(\mathrm{z})\right\}-\mathrm{E}\left\{\mathrm{Y}_{0} \mid \mathrm{R}=0, \mathrm{P}(\mathrm{z})\right\}\right]
$$

Where, $Y_{1}$ and $Y_{0}$ are outcomes for users and non-users of iCow services respectively; $R=1$ indicates that households use iCow services and $R=0$ refer to a comparison group of households that do not use iCow services.

PSM rests on two assumptions; one is the conditional independence assumption (CIA), which states that unobserved characteristics do not influence participation (Heckman, 1998). The second assumption is the Common Support Assumption (CSA), which seeks to develop a common support overlap of propensity scores for users and non-users of iCow services. Fulfillment of CSA ensures implies that participants and non-participants in the iCow services have similar observable characteristics for proper matching of subjects (Richard \& Monica, 2000; Khandker et al., 2010).

\subsection{Sampling Procedure and Data}

The study was implemented in Uasin Gishu, Nyandarua, and Bomet counties of Kenya, where iCow services have been in existence. The three counties were selected for the study because of the higher density of smallholder dairy farmers. The study used a two-stage stratified random sampling procedure to obtain respondents for the survey in the three counties. In the first stage, three dairy cooperatives, namely Sirikwa (Uasin Gishu), Olkalao (Nyandarua), and Siongiroi (Bomet) were purposively selected to form the sampling frame for users of iCow services. These are the counties that had been targeted by GDT for piloting and eventual rollout of the iCow services. Since GDT focused the entire membership of these cooperatives, it was not possible to find reasonable number of non-users of iCow services among members of the 3 dairy cooperatives. Moreover, any non-users may have been influenced in their livestock husbandry practices owing to their proximity to users. To reduce the challenge of spillovers, the study therefore also targeted three other dairy cooperatives within the same counties. These cooperatives had not participated in the iCow services and were identified approximately 15 kilometers from the dairy cooperatives that participated in the initial rollout of iCow services. These cooperatives were; Tarakwa, Miharati, and Ndanai in Uasin Gishu, Nyandarua, and Bomet, respectively and their members formed the sampling frame for non-users of ICow services.

In the second stage, respondents were randomly selected from the list of users of iCow service (members of the treated cooperatives) as well as non-user (members of control cooperatives where iCow services had not been piloted). The lists of members that formed the sampling frame in each case were obtained from the list of registered farmers as contained in the Kenya Dairy Farmers Federation (KDFF) registry. This resulted in a sample of 457 respondents, of which 209 farmers are regular users of iCow services, and 248 farmers were not enrolled in the platform.

Data were collected through personal interviews using a pre-tested questionnaire and administered using the Open Data Kit (ODK) platform. The household survey was conducted in June and July 2018, and information on farm-specific characteristics, farmers-specific characteristics, animal details, location characteristics, and household income were collected, the summary of which is contained in Table 1.

\section{Results}

\subsection{Descriptive Analysis}

Table 1 presents some of the descriptive statistics that reveal differences between users and non-users of iCow in outcome variables and other variables that have been used in the analysis. The t- values suggest that there are significant differences between the users of iCow and no-users with respect to milk production. Users realized higher average annual milk production per cow (2359.32 liters) as compared to non-users (1964.01 liters). 
There are also significant differences in incomes earned by households with users of iCow services earning Ksh 50,625 and 132,031 more milk incomes and household income respectively than the non-users.

Table 1. Differences in means for users of iCow and non-users of iCow

\begin{tabular}{|c|c|c|c|}
\hline Variable & Treated & Control & Differences \\
\hline \multicolumn{4}{|l|}{ Outcome Variable } \\
\hline Annual Milk production per cow (Litres) & 2359.32 & 1964.01 & $395.31 * * *$ \\
\hline Annual Milk income (Ksh) & 148277 & 97651 & $50625 * * *$ \\
\hline Annual Household income (Ksh) & 411107 & 279075 & $132031 * * *$ \\
\hline \multicolumn{4}{|l|}{ Independent Variables } \\
\hline Household head Education (Year) & 09.85 & 8.35 & $1.49 * * *$ \\
\hline Household head Experience in Dairy farming (years) & 12.78 & 13.00 & -0.22 \\
\hline Household head Age (years) & 43.77 & 44.87 & 1.09 \\
\hline Plot size under Dairy enterprise (Acres) & 1.72 & 1.31 & $0.41 * * *$ \\
\hline Number of lactating cows & 1.93 & 1.63 & 0.30 \\
\hline Number of breeds kept & 1.15 & 0.97 & $0.17 * * *$ \\
\hline Distance from the farm to the road $(\mathrm{Km})$ & 2.46 & 1.63 & $2.75 * * *$ \\
\hline Membership period to Dairy cooperative(years) & 7.54 & 6.54 & $1.00 * *$ \\
\hline Household head Gender $(1=$ Male, $0=$ Female $)$ & 0.76 & 0.70 & 0.05 \\
\hline Growing fodder $(1=$ Yes, $0=$ No $)$ & 0.70 & 0.60 & $0.100^{* *}$ \\
\hline Breed-type $(1=$ pure-exotic, $0=$ Otherwise $)$ & 0.40 & 0.28 & $0.12 * *$ \\
\hline Access to extension services $(1=$ Yes, $0=$ No $)$ & 0.62 & 0.54 & 0.07 \\
\hline Access to internet services $(1=\mathrm{Yes}, 0=\mathrm{No})$ & 0.37 & 0.19 & $0.17 * * *$ \\
\hline Milking $(1=$ Yes, $0=$ No $)$ & 0.96 & 0.93 & 0.02 \\
\hline Access to Credit services $(1=$ Yes, $0=\mathrm{No})$ & 0.31 & 0.25 & 0.06 \\
\hline Membership to other social groups $(1=\mathrm{Yes}, 0=\mathrm{No})$ & 0.40 & 0.29 & $0.10 * *$ \\
\hline Occupation $(1=$ Farmer, $0=$ Otherwise $)$ & 0.71 & 0.73 & -0.01 \\
\hline Marital status $(1=$ Married, $0=$ Otherwise $)$ & 0.81 & 0.81 & 0.00 \\
\hline Household Decisionmaker $(1=$ Joint, $0=$ Otherwise $)$ & 0.39 & 0.54 & $0.15^{* * *}$ \\
\hline
\end{tabular}

Note. ***Significant at 1\% level, ** Significant at 5\% level and * Significant at $10 \%$ level.

On average, users of iCow had significantly more years of schooling; about ten years as compared to 8 years for the non-users. As for age, the average age of household head for users of iCow was 44 years while that of non-users was 45. The difference is, however, insignificant. At the time of this study, over $90 \%$ of the households had lactating cows, with each household keeping at least 2 lactating cows on average. Most of these cows were crossbreeds. With regards to membership to the dairy cooperative, most respondents interviewed belonged to dairy cooperatives, but iCow users had been members for significantly more extended periods than non-users of iCow services; average membership duration of 7 years for iCow users and 6 years for non-users. In terms of the gender of household head, most households were headed by males, even though there were significantly more male-headed households among users of iCow services (76\%) than among non-users (70\%).

On average, more iCow users had access to extension services (62\%) compared to non-user (54\%). This difference is, however, insignificant. These extension services are mainly provided by the extension agents belonging to the dairy cooperatives. With regards to accessing internet services, significantly more users of iCow users had access; about 37\% compared to just $19 \%$ among non-users of iCow services. The low percentage across the board is probably due to the fact that most farmers live in remote areas where network connectivity is a challenge. Some of the farmers may also be in possession of phones that are unable to access internet services. These findings are similar to (Chilimo, 2009) who revealed that low network connectivity and low power supply are the main constraints that affect use of ICTs among farmers.

In relation to plot size under dairy enterprise, iCow users had significantly more acreage of their total land allocated to the dairy enterprise compared to the non-users. Additionally, more than $50 \%$ of the households interviewed grow their own fodder with nappier grass being a dominant fodder in the study regions. 


\subsection{Challenges Facing Both iCow Users and Non-users}

Results from Figure 1 show various challenges both iCow users and non-users face in dairy production. Most farmers stated that feed shortages were the major challenge they faced, followed by livestock diseases and the high cost of feeds. Feed shortages can be explained by the fact most farmers in the study areas own small pieces of land that have been subdivided, making it a challenge to grow enough fodder. The reported high percentage of livestock diseases is because of the East Coast Fever (ECF) disease in the counties which has become a hindrance to optimal production and earnings among dairy farmers.

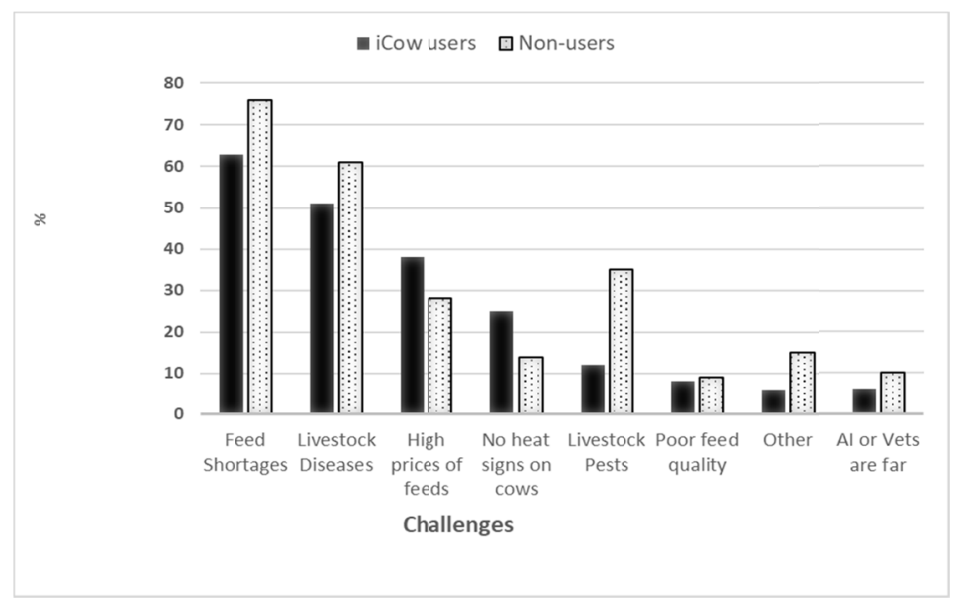

Figure 1. Various challenges dairy farmers face among the iCow users and non-users

Figure 2 presents results on the various iCow messages mainly put into practice once the farmers receive them. Most farmers reported that they had focused so much on practicing the tips on fodder management. This pattern can be explained in Figure 1, which pointed out that the significant challenge that both iCow users and non-users face is feed shortages. Therefore, most farmers focused on these messages by putting into practice the information that would give a solution.

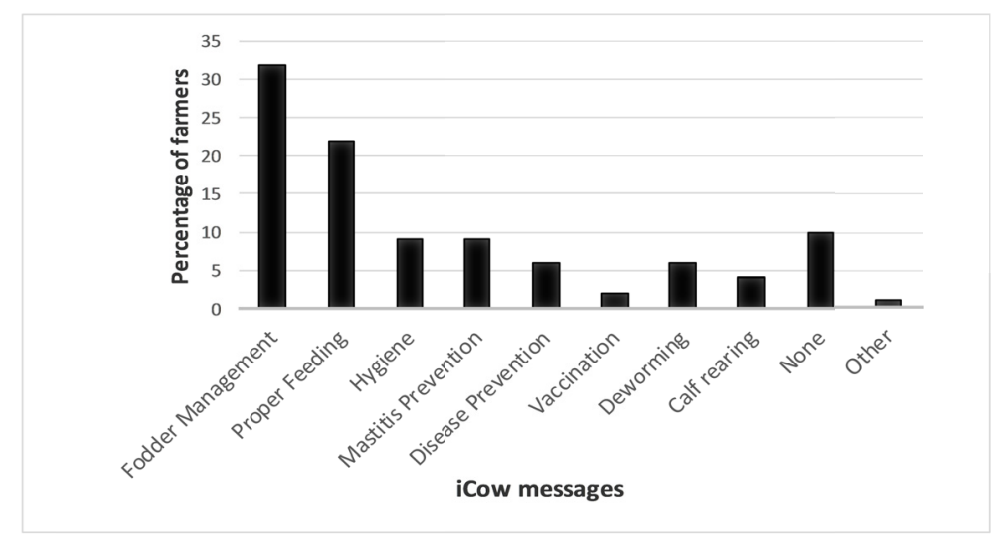

Figure 2. Various iCow words mainly put into practice by regular users of iCow

Results from Figure 3 shows that $57 \%$ of the farmers interviewed reported that hygiene had improved due to the information from iCow. Followed by $55 \%$ and $37 \%$ of the farmers stating that feeding had improved and had managed to control mastitis, respectively. These changes were highly noticed because, at many times, dairy farmers do suffer from lack of knowledge on nutrition, hygiene and how to control mastitis. With the information they receive from iCow, they were able to put it into practice resulting in observed changes. 


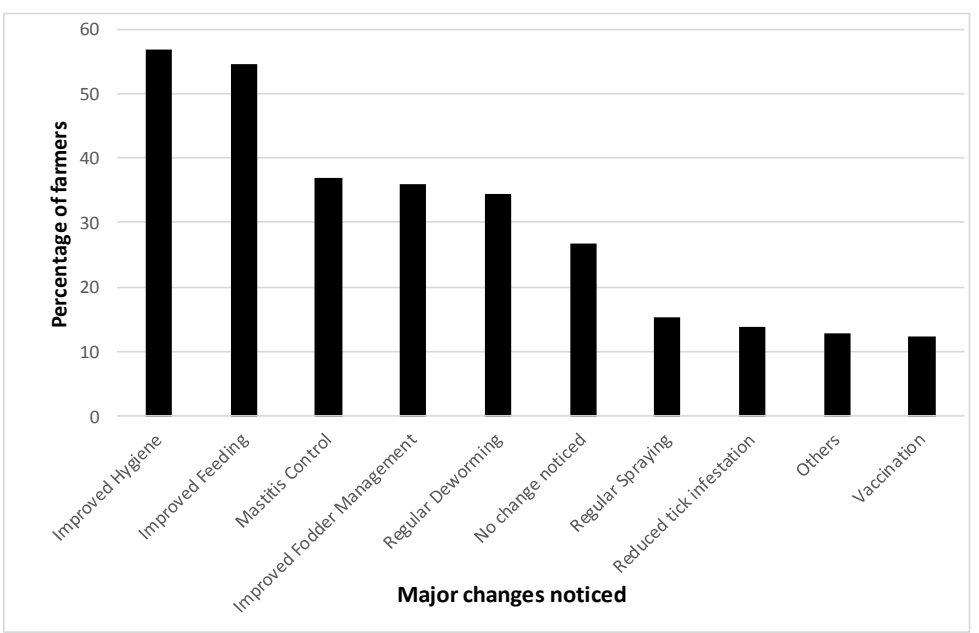

Figure 3. Changes noticed by iCow users after using the messages received from iCow

\subsection{Impact of iCow Services}

While the descriptive statics in Table 1 show differences in several variables between users and non- users of iCow services, one can hardly attribute the differences to the use of iCow services until the data is subjected to rigorous impact evaluation. In this sub-section, we discuss the results of the PSM estimation of the impact of iCow service on milk production, milk income, and household income. First, a logit model was employed to predict the probability of households participating in the iCow platform, results of which are presented in Table 2.

Table 2. A logit model of determinants of participation in the iCow program

\begin{tabular}{|c|c|c|c|c|}
\hline Variable & Coefficient & dy/dx & S. E & P-value \\
\hline Household head Gender $(1=$ Male, $0=$ Female $)$ & 0.210777 & 0.0403317 & 0.256907 & 0.412 \\
\hline Household head Education (Year) & $0.0762672 * * *$ & $0.0145936^{* * *}$ & 0.0261261 & 0.004 \\
\hline Household head Age (years) & -0.0103845 & -0.001987 & 0.0080844 & 0.199 \\
\hline Experience in Dairy farming (years) & -0.0013415 & -0.0002567 & 0.0130979 & 0.918 \\
\hline Growing fodder $(1=$ Yes, $0=\mathrm{No})$ & 0.1838024 & 0.0351702 & 0.2423104 & 0.448 \\
\hline Membership to Dairy cooperative(years) & $2.983539^{* * *}$ & $0.5708932 * * *$ & 1.049018 & 0.004 \\
\hline Access to extension services $(1=$ Yes, $0=\mathrm{No})$ & -0.0606871 & -0.011612 & 0.2321239 & 0.794 \\
\hline Access to internet services $(1=\mathrm{Yes}, 0=\mathrm{No})$ & $0.6520559 * * *$ & $0.1247694 * * *$ & 0.2548575 & 0.008 \\
\hline Milking $(1=$ Yes, $0=$ No $)$ & 0.6696489 & 0.128135 & 0.5982336 & 0.263 \\
\hline Number of Lactating cows & $0.3269762 * *$ & $0.0625661 * *$ & 0.1346353 & 0.012 \\
\hline Access to Credit services $(1=$ Yes, $0=\mathrm{No})$ & 0.1851316 & 0.0354245 & 0.2484814 & 0.456 \\
\hline Plot size under Dairy enterprise (Acres) & $0.2873967 * * *$ & $0.0549927 * * *$ & 0.1149882 & 0.010 \\
\hline Membership to other social groups $(1=$ Yes, $0=$ No $)$ & $0.4995711^{* *}$ & $0.0955918^{* *}$ & 0.2345287 & 0.030 \\
\hline Membership period to Dairy cooperative(years) & $0.0436539 * *$ & $0.0083531 * *$ & 0.0215538 & 0.039 \\
\hline Occupation $(1=$ Farmer, 0 = Otherwise $)$ & -0.3563509 & -0.0681869 & 0.2763241 & 0.197 \\
\hline Marital status $(1=$ Married, $0=$ Otherwise $)$ & 0.1434172 & 0.0274425 & 0.3003813 & 0.633 \\
\hline Household Decisionmaker ( $1=$ Joint , $0=$ Otherwise $)$ & $-0.4498008^{* *}$ & $-0.08606^{* *}$ & 0.2314903 & 0.048 \\
\hline Breed type $($ Local $=1, \quad$ Otherwise $=0)$ & $1.055652^{* *}$ & $0.2019966^{* *}$ & 0.4818823 & 0.025 \\
\hline Distance from the farm to the road $(\mathrm{Km})$ & -0.0020488 & -0.000392 & 0.0058846 & 0.728 \\
\hline Number of breeds & $0.8289937^{*}$ & $0.158626^{*}$ & 0.4398011 & 0.056 \\
\hline Constant & -6.453247 & & 1.325588 & 0.000 \\
\hline Log likelihood & -254.17437 & & & \\
\hline LR chi2(26) & 120.63 & & & \\
\hline Prob > chi 2 & 0.0000 & & & \\
\hline Pseudo R2 & 0.1918 & & & \\
\hline Observations & 456 & & & \\
\hline
\end{tabular}

Note. ***Significant at $1 \%$ level, $* *$ Significant at 5\% level and * Significant at $10 \%$ level. 
Results from Table 2 indicate that several variables do influence the likelihood of households adopting the use of iCow services. In particular, level of education, membership to the dairy cooperative, access to internet services, number of lactating cows, land size under dairy enterprise, membership to other social groups, membership period to dairy cooperatives, breed type and number of breeds kept have a significant and positive effect on the adoption and use of iCow services. However, joint decision making at household level seems to affect the use of iCow services negatively.

Figure 4 shows the distribution of the estimated scores of PSM and the support region. The visual analysis showing the density of distribution for the treated and control groups as suggested by (Caliendo \& Kopeinig, 2008) indicate that a majority of the treated and control individuals fall within the standard support region. In other words, most individuals had a positive probability of being users of iCow services. The support assumption (CSA) is, therefore satisfied, indicating that treated households had corresponding matches among the control households.

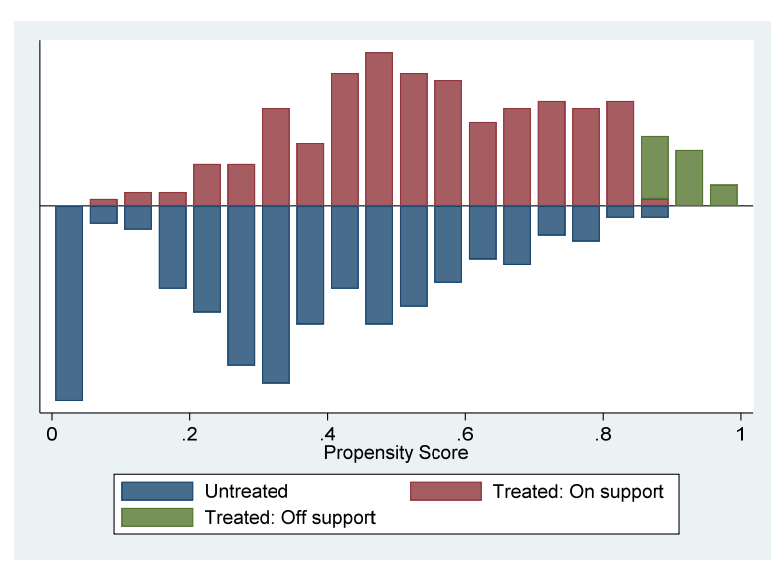

(a) Nearest Neighbour matching

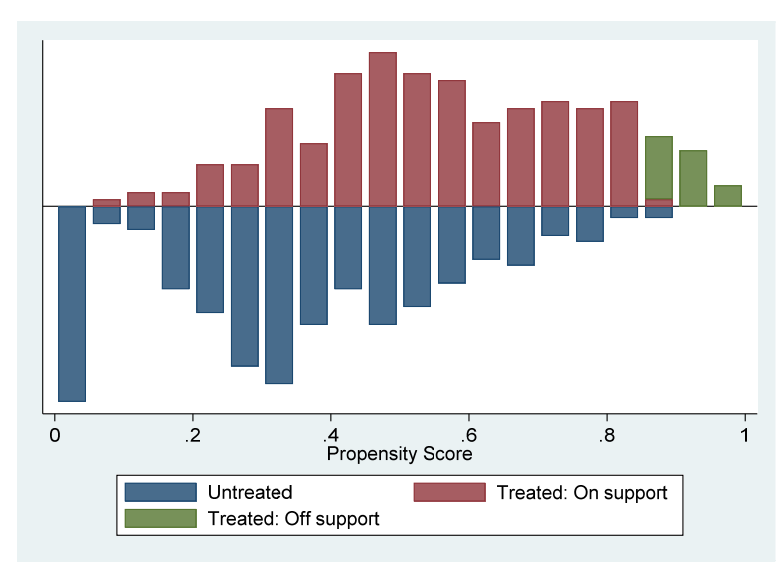

(b) Kernel-based matching

Figure 4. Distribution of the estimated propensity scores and the common support region

The results of the PSM model for quantifying the impact of iCow services on milk production and incomes are estimated with Nearest Neighbor Matching (NNM) and Kernel-based matching (KBM). In literature, various matching methods have been employed; however, in this study, we use the most common ones; Nearest neighbor matching (NNM) and Kernel-based matching (KBM), which are useful in checking the robustness of the results.Estimation results are presented in Table 3. We find that the use of iCow services has a significant and positive impact on milk production and household income. Based on the findings, we reject the null hypothesis that there is no significant difference between iCow users and non-users in terms of milk production and incomes and conclude that the iCow services had a significant influence on the stated outcome variables.

The average treatment effect on the treated (ATT) for the milk production per cow ranges between 298.15 liters (based on NNM) and 323.10 liters (based on KBM). The treatment effect is also significant at $5 \%$ for the NNM and at $1 \%$ for the KBM. The increment in milk production per cow can be attributed to iCow users being able to apply knowledge on husbandry practice that they acquire via use of iCow extension advise. These results are consistent with the findings by Das et al. (2016), which showed that use of ICT in accessing agricultural information increased production of rice in Bangladesh. Similarly, Hopestone (2014) and Ali et al. (2016) showed that use of ICT in agriculture has a positive impact on productivity.

We also find that the use of iCow services significantly increases milk income by between Ksh. 38,727 and Ksh. 38,309 . It is likely that application of knowledge on livestock practices as advised via iCow services improves milk yield resulting in more surpluses for sale by farmers. The findings are similar to those of John and Barclay (2017) and Meydani (2017) who pointed out that the use of mobile phones among farmers in accessing agricultural information had positive impact on their income and productivity.

Additionally, impacts on annual household income are even high (Ksh. 62,381 to Ksh. 89,043) indicating a multiplier effect of iCow services. These results imply that revenue generated from dairy enterprise due to the use of iCow services are re-invested by households in further income-generating opportunities. A similar 
observation was made by Halewood and Surya (2012), who showed that use of ICTs in accessing information led to increasing of farmers' income by up to $36 \%$ in countries such as Kenya, Ghana, Uganda, and Morocco. Also, Manyika et al. (2013) conclude that use of SMS by the Ethiopian Commodity exchange provided transparency on demand, supply, and prices and this increased farmers' share of revenue.

Following the results in Table 3, it can be argued that iCow positively influenced access to agricultural knowledge, leading to improved yields and increased surpluses that are sold for increased dairy income. This would subsequently impact household income depending on the role of dairy in a household income portfolio.

Table 3. Average treatment effects and results of sensitivity analysis

\begin{tabular}{|c|c|c|c|c|c|c|c|c|c|}
\hline \multirow{2}{*}{ Outcome Variable } & \multirow{2}{*}{$\begin{array}{l}\text { Matching } \\
\text { algorithm }\end{array}$} & \multirow{2}{*}{ Treated } & \multirow{2}{*}{ Control } & \multirow{2}{*}{ ATT } & \multirow{2}{*}{ SE } & \multirow{2}{*}{$\begin{array}{l}\text { Bias } \\
(\text { gamma })\end{array}$} & \multicolumn{2}{|c|}{ Matched Observations } & \multirow{2}{*}{ Total } \\
\hline & & & & & & & Treatment & Control & \\
\hline \multirow{2}{*}{$\begin{array}{l}\text { Annual milk production } \\
\text { per cow (Litres) }\end{array}$} & Neighbour matching & 2337.89 & 2039.73 & $298.15 * *$ & 162.96 & $1.20-1.25$ & 189 & 247 & 436 \\
\hline & Kernel matching & 2337.89 & 2014.78 & $323.10 * * *$ & 133.45 & $1.35-1.40$ & 189 & 247 & 436 \\
\hline \multirow{2}{*}{ Annual Milk income (Ksh) } & Neighbour matching & 140336 & 101608 & $38727 * * *$ & 11365 & $1.45-1.50$ & 189 & 247 & 436 \\
\hline & Kernel matching & 140336 & 102026 & $38309 * * *$ & 9990 & $1.40-1.45$ & 189 & 247 & 436 \\
\hline \multirow{2}{*}{ Annual Household income (Ksh) } & Neighbour matching & 398907 & 336526 & $62381 *$ & 70984 & 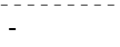 & 189 & 247 & 436 \\
\hline & Kernel matching & 398907 & 309863 & $89043 * *$ & 44870 & - & 189 & 247 & 436 \\
\hline
\end{tabular}

\subsection{Testing for the Robustness of Results}

\subsubsection{Covariate Balancing}

While the PSM procedure has the ability to control for selection bias, the estimates are only valid if two conditions are met: (i) balancing in covariates is achieved, and (ii) there is no systematic farmer heterogeneity due to unobservable (Caliendo \& Kopeinig, 2008; Dehejia, 2002). The PSM estimation procedure aims to balance the distribution of variables relevant to the matching process in order to construct comparable groups. Balancing tests are therefore necessary after matching to establish if the matching process has indeed reduced the bias by eliminating differences in covariates. Only if this is achieved can the matched comparison group be considered as a plausible counterfactual (Caliendo \& Kopeinig, 2008). We evaluate the balancing condition and bias reduction following (Rosenbaum \& Rubin, 1985).

Table 4 presents the results of the covariates balancing, which was used to confirm the validity of the matching algorithms used to match the users of iCow and non-users. The results indicate that the majority of the covariates had insignificant differences after matching in all the matching methods as shown by the p-values under matched sample. This implies no systematic differences in these covariates, which confirms that a good counterfactual was generated by the matching process. Table 5 summarizes indicators of covariate balancing before and after matching. The results reveal substantial reduction of bias for both matching methods (78-89\%). The pseudo $\mathrm{R}^{2}$ and $\mathrm{p}$-values of the likelihood ratio tests before and after matching are also presented in Table 5 . The joint significance of regressors is rejected after matching, while it is not dismissed before matching. This underlines that systematic differences that are due to observable factors are properly eliminated.

\subsubsection{Testing for Sensitivity Analysis}

We also test for sensitivity of our results to hidden bias using Rosenbaum bounds (Rosenbaum, 1999; Hujer et al., 2004). Assuming two individuals have the same observed covariates $\boldsymbol{z}$ (as implied by the matching procedure), the two matched observations would differ in their odds of using the iCow services only by the difference in unobserved covariates, measured by the parameter $\Gamma$. The procedure involves changing the level of $\Gamma$ and deriving the bounds on the significance levels of the ATT under the assumption of endogenous self-selection into the use of iCow services. This allows for identification of the critical levels of $\Gamma$ at which the estimated ATT would become insignificant. The results of these bounding test are presented in Table 3 with the essential levels of gamma where the significant impact of iCow may be questioned.

Results show that the impact estimates are relatively insensitive to hidden bias in the outcome variables. For example, for the impact of iCow on milk production, the sensitivity analysis shows that at the gamma level of 1.20 to 1.40 , ATT due to the use of iCow would need to be viewed critically. These critical values of gamma imply that if individuals who have similar observable covariates will differ in their odds of using iCow services due to unobserved heterogeneity by $20-40 \%$, then the significant effect of iCow services on milk production may be questionable. The lowest critical value of gamma is $1.20-1.25$, whereas the largest is $1.45-1.50$. These 
critical levels are pretty high. We can therefore conclude that our results are robust to unobserved heterogeneity among respondents.

Table 4. Results of covariate balance tests for propensity scores using NNM and KBM algorithms

\begin{tabular}{|c|c|c|c|c|c|c|c|c|c|c|}
\hline \multirow{2}{*}{ Variables } & \multicolumn{5}{|c|}{ Mean (NNM) } & \multicolumn{5}{|c|}{ Mean (KBM) } \\
\hline & Treated & Control & $\%$ Bias & \%Reduction & $\mathbf{p}>|\mathbf{t}|$ & Treated & Control & $\%$ Bias & \%Reduction & $\mathbf{p}>|\mathbf{t}|$ \\
\hline Household head Gender $(1=$ Male, $0=$ Female $)$ & 0.76 & 0.75 & 0.6 & 94.5 & 0.95 & 0.7619 & 0.72752 & 7.8 & 28.7 & 0.445 \\
\hline Household head Education (Year) & 9.70 & 9.94 & -5.1 & 84.4 & 0.62 & 9.709 & 8.9726 & 15.8 & 51.1 & 0.129 \\
\hline Experience in Dairy farming (years) & 12.79 & 13.49 & -7.3 & -190.3 & 0.46 & 12.79 & 12.773 & 0.2 & 93.1 & 0.986 \\
\hline Growing fodder $(1=$ Yes, $0=$ No $)$ & 0.69 & 0.60 & 20.7 & 10.2 & 0.04 & 0.69841 & 0.63998 & 12.3 & 46.4 & 0.228 \\
\hline Membership to dairy cooperative $(1=\mathrm{Yes}, 0=\mathrm{No})$ & 0.99 & 0.99 & 1 & 98.2 & 0.75 & 0.99471 & 0.95955 & 13.6 & 75.8 & 0.022 \\
\hline Access to extension services $(1=$ Yes, $0=$ No $)$ & 0.62 & 0.61 & 1.6 & 89.5 & 0.87 & 0.62434 & 0.57832 & 9.3 & 39 & 0.362 \\
\hline Access to internet services $(1=\mathrm{Yes}, 0=\mathrm{No})$ & 0.34 & 0.37 & -7.8 & 80.8 & 0.48 & 0.34392 & 0.24537 & 22.3 & 44.9 & 0.036 \\
\hline Milking $(1=$ Yes, $0=$ No $)$ & 0.96 & 0.95 & 2.5 & 80.6 & 0.79 & 0.96296 & 0.95762 & 2.5 & 80.4 & 0.791 \\
\hline Number of Lactating cows & 1.89 & 1.81 & 9.5 & 73.7 & 0.40 & 1.8942 & 1.7041 & 22.7 & 37.1 & 0.30 \\
\hline Access to Credit services $(1=$ Yes, $0=$ No $)$ & 0.31 & 0.31 & 0.6 & 95.9 & 0.95 & 0.31746 & 0.28676 & 6.8 & 52.6 & 0.517 \\
\hline Plot size under Dairy enterprise (Acres) & 1.47 & 1.52 & -3.1 & 89.1 & 0.69 & 1.4788 & 1.3325 & 10.1 & 64.6 & 0.139 \\
\hline Membership to other social groups $(1=\mathrm{Yes}, 0=\mathrm{No})$ & 0.38 & 0.39 & -1.7 & 92.2 & 0.87 & 0.38624 & 0.33383 & 11 & 48.8 & 0.29 \\
\hline Membership period to Dairy cooperative (years) & 7.67 & 7.53 & 2.5 & 87.1 & 0.81 & 7.672 & 6.7422 & 17.6 & 9.1 & 0.106 \\
\hline Occupation $(1=$ Farmer, $0=$ Otherwise $)$ & 0.70 & 0.69 & 1.2 & 64.9 & 0.91 & 0.7037 & 0.72462 & -4.7 & -38.6 & 0.654 \\
\hline Marital status ( $1=$ Married, 0 = Otherwise $)$ & 0.81 & 0.80 & 3.4 & -259.4 & 0.74 & 0.81481 & 0.79727 & 4.5 & -376.8 & 0.667 \\
\hline Decisionmaker ( 1 = Joint , $0=$ Otherwise $)$ & 0.40 & 0.39 & 2.1 & 93 & 0.834 & 0.40212 & 0.45142 & -10 & 67.2 & 0.334 \\
\hline Keep Dairy Local Breed $(1=$ Yes, $0=$ No) & 0.09 & 0.10 & -2.7 & 93.5 & 0.797 & 0.09524 & 0.05704 & 12.9 & 68.7 & 0.162 \\
\hline Keep Dairy pure exotic Breed $(1=$ Yes, $0=$ No $)$ & 0.38 & 0.317 & 14.6 & 46 & 0.162 & 0.38624 & 0.32719 & 12.5 & 53.6 & 0.232 \\
\hline
\end{tabular}

Table 5. Results for statistical significance of matching algorithms

\begin{tabular}{|c|c|c|c|c|c|c|c|}
\hline \multirow[b]{2}{*}{ Matching Algorithm } & \multicolumn{3}{|c|}{ Median Bias } & \multicolumn{2}{|c|}{ Pseudo R2 } & \multicolumn{2}{|c|}{ p-Value of LR } \\
\hline & $\begin{array}{l}\text { Before } \\
\text { Matching }\end{array}$ & $\begin{array}{l}\text { After } \\
\text { Matching }\end{array}$ & $\begin{array}{l}\% \text { Bias } \\
\text { Reduction }\end{array}$ & Unmatched & Matched & Unmatched & Matched \\
\hline Nearest Neighbour Matching & 22.3 & 2.6 & 89 & 0.185 & 0.019 & 0.0000 & 0.938 \\
\hline Kernel-based Matching & 22.3 & 10.6 & 78 & 0.185 & 0.058 & 0.0000 & 0.033 \\
\hline
\end{tabular}

\section{Conclusion and Policy Implications}

The study employed PSM to examine the effects of the use of iCow services on milk production, incomes using cross-sectional data from dairy farmers in three counties of Kenya. Overall, the findings indicate that use of iCow services among dairy farmers has a positive and significant effect on milk production and income. The figures reveal that application of iCow services leads increase in milk production per cow, milk income and household income by $13 \%, 29 \%$ and $22 \%$ respectively, which can also be considered as an opportunity cost of not using iCow service. This positive impact shows the potential role of ICT-based extension in rural poverty reduction through increased household incomes. Therefore, these findings highlight the need to scale up the iCow services, due to its proven capacity of enhancing smallholder farmers' access to simple, timely information and digital solution, subsequently improving their production, incomes.

These findings also imply that ICT tools that enhance access and delivery of farm information should be integrated into the programs that aim at improving farm productivity and incomes. The positive correlation of use of phones in getting timely information among farmers suggests that policies should focus on improving infrastructure in the rural areas for the ICT usage: this includes, expansion of electrification programs for access to power for charging the ICT devices. Besides, there is also a need for development of mobile network coverage in the rural areas where the network is poor to facilitate exchange of information in uninterrupted manner.

Finally, partnerships between network providers and research institutes should be encouraged as part of bridging the extension gap occasioned by reduced public expenditure on extension services. It is through this that that research institutes will get the chance to refine the content of the e- extension approaches to meet the needs of farmers. 


\section{References}

Ajani, E. N., \& Agwu, A. E. (2012). Information Communication Technology Needs of Small-Scale Farmers in Anambra State, Nigeria. Journal of Agricultural and Food Information, 13(2), 144-156. https://doi.org/ 10.1080/10496505.2012.663694

Ali, S., Jabeen, U. A., \& Nikhitha, M. (2016). Impact of ICTs on Agriculture Productivity. European Journal of Business, Economics and Accountancy, 4(5), 82-92.

Babcock, B. A., \& Hennessy, D. A. (1996). Input Demand under Yield and Revenue Insurance. American Journal of Agricultural Economics, 78(2), 416. https://doi.org/10.2307/1243713

Caliendo, M., \& Kopeinig, S. (2008). Some practical guidance for the implementation of propensity score matching. Journal of Economic Surveys, 22(1), 31-72. https://doi.org/10.1111/j.1467-6419.2007.00527.x

Chilimo. (2009). Developing online research strategies for library users at Sokoine National Agricultural Library in Tanzania: The role of Information literacy programs.

Das, B. (2014). ICTs Adoption for Accessing Agricultural Information: Evidence from Indian Agriculture. Agricultural Economics Research Review, 27(2), 199. https://doi.org/10.5958/0974-0279.2014.00024.X

Das, S., Munshi, M. N., \& Kabir, W. (2016). The Impact of ICTS on Agricultural Production in Bangladesh: A Study with Food Crops. SAARC J. Agri., 14(2), 78-89. https://doi.org/10.3329/sja.v14i2.31247

Dehejia, R. H. W. S. (2002). PSM methods for nonexperimental causal studies. The Review of Economcs and Statistics, 84(1), 151-161. https://doi.org/10.1162/003465302317331982

Duncombe, R. (2012). Mobile Phones for Agricultural and Rural Development: A Literature Review and Suggestions for Future Research. Eur. J. Dev. Res., 28, 213-235. https://doi.org/10.1057/ejdr.2014.60

Fu, X., \& Akter, S. (2012). Impact of Mobile Telephone on the Quailty and Speed of Agricultural Extension Services Delivery: Evidence from Rural e-services Project in India (pp. 1-30). International Association of Agricultural Economists (IAAE) 2012 Triennial Conference.

Gómez-Limón, J. A., Riesgo, L., \& Arriaza, M. (2004). Multi-criteria analysis of input use in agriculture. Journal of Agricultural Economics, 55(3), 541-564. https://doi.org/10.1111/j.1477-9552.2004.tb00114.x

Halewood, N. J., \& Surya, P. (2012). Mobilizing the Agricultural Value Chain. Information and Communications for Development, August 2012, 31-44. https://doi.org/10.1596/9780821389911_ch02

Hassan, S., Hassan, M. A., Samah, B. A., \& Ismail, N. (2008). Use of Information and Communication Technology (ICT) among Agri-based Entrepreneurs in Malaysia. World Conference on Agricultural Information and IT.

Heckman, J. J. (1998). Fundacao de Apoio a Universidade do Rio Grande A/C Karina (p. 53).

Heckman, J., \& Navarro-Lozano, S. (2004). Functions To Estimate Economic Choice Models. Statistics, 86, 30-57. https://doi.org/10.1162/003465304323023660

Hopestone, K. C. (2014). The role of ICTs in agricultural production in Africa. Journal of Development and Agricultural Economics, 6(7), 279-289. https://doi.org/10.5897/JDAE2013.0517

Hujer, R., Caliendo, M., \& Thomsen, S. L. (2004). New evidence on the effects of job creation schemes in Germany-A matching approach with threefold heterogeneity. Research in Economics, 58(4), $257-302$. https://doi.org/10.1016/j.rie.2004.07.001

Ichimura, H., Review, T. T., Studies, E., \& Global, I. (1997). Matching as an econometric evaluation estimator: Evidence from evaluating a Job Training Program. The Review of Economic Studies, 64(4), 605-54. https://doi.org/10.2307/2971733

John, A., \& Barclay, F. P. (2017). ICT usage and effects among rural farming communities. Journal of Media and Communication, 1(1), 100-136.

Joseph, O. C., \& Polytechn, O. (2017). Effectiveness of Extension Services in Enhancing the Productivity, Income and Welfare of Women Farmers Cooperatives in Kajuru Local Government Area of Kaduna State. International Journal of Economics and Business Management, 3(8), 86-100.

Khandker, S., Gayatri, B. K., \& Hussain, S. (2010). Handbook on Impact Evaluation. The World Bank. https://doi.org/10.1596/978-0-8213-8028-4 
Maddala, G. S. (1991). A Perspective on the Use of Limited-Dependent and Qualitative Variables Models in Accounting Research. The Accounting Review, 66(4), 788-807.

Manyika, J., Cabral, A., Moodley, L., Moraje, S., Yeboah-Amankwah, S., Chui, M., \& Anthonyrajah, J. (2013). Lions go digital: The Internet's transformative potential in Africa (pp. 1-124). McKinsey Global Institute.

Meydani, E. (2017). Role of Information and Communication Technologies in Government Effectiveness. ICEGOV'17: Proceedings of the 10th International Conference on Theory and Practice of Electronic Governance (pp. 494-503). https://doi.org/10.1145/3047273.3047311

Milu, M., \& Jayne, T. S. (2006). Agricultural Extension in Kenya: Practice and Policy Lessons. The Journal of Agricultural Education and Extension, 14(2), 111-124. https://doi.org/10.1080/13892240802019063

Mukembo, S., \& Edwards, M. C. (2016). Agricultural Extension in Sub-Saharan Africa During and After Its Colonial Era: The Case of Zimbabwe, Uganda, and Kenya. Journal of International Agricultural and Extension Education, 22(3), 50-68. https://doi.org/10.5191/jiaee.2015.22304

Nyaga, K. E. (2012). Is ICT in Agricultural Extension Feasible in Enhancing Marketing of Agricultural Produce in Kenya: A Case of Kiambu District. Quarterly Journal of International Agriculture, 51(3), 245-256.

Ogutu, S. O., Okello, J. J., \& Otieno, D. J. (2013). Impact of Information and Communication Technology-based Market Information Services on Smallholder Farm Input Use and Productivity: The Case of Kenya (pp. 22-25). International Conference of the African Association of Agricultural Economists (ICAAAE).

Oyeyinka, R. A., \& Bello, R. O. (2013). Farmers Use of Icts for Marketing Information Outlets in Oyo State, Nigeria. Journal of Agricultural Science, 5(11), 150. https://doi.org/10.5539/jas.v5n11p150

Ravallion, M. (2009). Bailing Out the World's Poorest. Challenge, 52(2), 55-80. https://doi.org/10.2753/ $0577-5132520203$

Richard, B., \& Monica, C. D. (2000). Evaluation Methods for Non-Experimental Data. Fiscal Studies, 21(4), 427-468. https://doi.org/10.1111/j.1475-5890.2000.tb00031.x

Rosenbaum, P. R. (1999). Design of Observational Studies. Springer Series in Statistics (pp. 153-161). https://doi.org/10.1007/978-0-387-98135-2

Rosenbaum, P. R., \& Rubin, D. B. (1985). Constructing a Control Group Using Multivariate Matched Sampling Methods That Incorporate the Propensity Score. The American Statistician, 39(1), 33-38. https://doi.org/ 10.1080/00031305.1985.10479383

Singh, S. (2006). Selected success stories on agricultural information systems. Asia-Pacific Association of Agricultural Research Institutions, Thailand.

Stearns, S. C. (2000). Daniel Bernoulli (1738): Evolution and economics under risk. Journal of Biosciences, 25(3), 221-228. https://doi.org/10.1007/BF02703928

Tata, J. S., \& Mcnamara, P. E. (2018). Impact of ICT on agricultural extension services delivery: Evidence from the Catholic Relief Services SMART skills and Farmbook project in Kenya. The Journal of Agricultural Education and Extension, 24(1), 89-110. https://doi.org/10.1080/1389224X.2017.1387160

Wooldrige, J. M. (2011). Econometric Analysis of Cross Section and Panel Data. Neurology Secrets, 7, i-ii.

\section{Copyrights}

Copyright for this article is retained by the author(s), with first publication rights granted to the journal.

This is an open-access article distributed under the terms and conditions of the Creative Commons Attribution license (http://creativecommons.org/licenses/by/4.0/). 